Institute of $\mathbf{F}_{\text {ood and }} \mathbf{A}_{\text {gricultural }} \mathbf{S}_{\text {ciences }}$

\title{
Manual de los Reglamentos del Agua de Florida: Acta de las Especies en Peligro de Extinción ${ }^{1}$
}

\author{
Michael T. Olexa, Laura Minton, Dulcy Miller, y Sarah Corbett ${ }^{2}$
}

\section{Agradecimientos}

Los autores agradecen a Richard Budell de la Oficina de Política del Agua Agrícola del Departamento de Agricultura y Servicios al Consumidor de Florida. Los autores también agradecen a David H. Hammonds, Consultor del Programa de Salud Ambiental, Oficina de Programas de Aguas de Drenaje en el Sitio, del Departamento de Salud de Florida, y a Edward A. Bettinger, Consultor del Programa de Salud Ambiental, Oficina de Programas de Agua del Departamento de Salud de Florida.

\section{Sinopsis}

El Acta de las Especies en Peligro de Extinción (AEPE) fue aprobada en 1974 para proteger los peces, vida silvestre, y plantas que están amenazados por la extinción y los ecosistemas que están definidos como críticos para su sobrevivencia. En muchos casos, estos ecosistemas son pantanos, así que la protección de las especies en extinción frecuentemente equivale a la protección del agua.

\section{¿Quien Aplica la AEPE?}

La AEPE exige que todas las agencias consulten con el correspondiente departamento federal (como el Departamento del Interior, USDA) para determinar que efectos del uso de la tierra u otras acciones, tendrán sobre las especies en peligro. Las agencias

1. Este es el documento EDIS FE071, una publicación del Department of Food and Resource Economics, Florida Cooperative Extension Service, Institute of Food and Agricultural Sciences, University of Florida, Gainesville, FL. Publicada Noviembre 2002. Por favor visite la página electrónica EDIS en http://edis.ifas.ufl.edu.

2. Michael T. Olexa, es profesor del Department of Food and Resource Economics, Florida Cooperative Extension Service, Institute of Food and Agricultural Sciences, University of Florida, Gainesville, FL; y miembro de Florida Bar; Presidente de Agricultural Law Committee of The Florida Bar; y Director del Agricultural Law Center. Laura Minton, Dulcy Miller, y Sarah Corbett son estudiantes graduadas de Levin College of Law, University of Florida, Gainesville, FL. Filiberto Reyes-Villanueva fue el traductor de la versión en ingles al español.

Esta publicación esta diseñada para proporcionar información precisa, actualizada y autorizada sobre esta material. Sin embargo, ya que las leyes, reglas administrativas y decisiones de la corte, sobre las cuales están basados, están sujetas a revisión constante; algunas partes de esta publicación podrían ser obsoletas en cualquier momento. Esta publicación es distribuida bajo el entendimiento que los autores no están involucrados en ninguna representación legal u otros servicios profesionales, y que la información contenida aquí no debe ser considerada como un substituto de una asesoria legal. Esta publicación no esta completa en proporcionar toda la información para lograr el cumplimiento de las leyes y reglamentos que gobiernan la protección del agua. Por estas razones, el uso de estos manuales por cualquier persona constituye un acuerdo para mantener libre de daño a los autores, al Florida Cooperative Extension Service, al Institute of Food and Agricultural Sciences, y a la University of Florida por cualquier demanda por responsabilidad de daños, o gastos en que pueda incurrir cualquier persona, como un resultado de hacer referencia o confianza sobre la información contenida en esta publicación. Esta publicación fue apoyada financieramente por el Florida Department of Agriculture and Consumer Services.

El Instituto de Alimentos y Ciencias Agrícolas es Un empleador que opera bajo Acción Afirmativa y provee Oportunidades Igualitarias, dedicado a promocionar la investigación, a información educativa y otros servicios, únicamente a los individuos e instituciones que operan baj discriminación sin considerar color, raza, sexo, edad, incapacidad u origen. Para más información sobre como obtener otras publicaciones de la extensión, comuníquese con la oficina de Servicio de Extensión de su condado. Servicio de Extensión de la Florida / Instituto de Alimentos y Ciencias Agrícolas / Universidad de la Florida / Christine Taylor Waddill, Decana. 
tienen prohibido tomar cualquier acción que amenacen a una especie en peligro, sin un especial permiso de un comité encabezado por el Secretario del Interior.

La acción de la agencia puede incluir la emisión de un permiso a una parte privada, tal como cuando el Cuerpo de Ingenieros emite permisos para actividades de drenado y relleno (Ver la sección del Acta de Agua Limpia). La AEPE también se aplica a acciones del estado y privadas, aunque las prohibiciones son ligeramente diferentes.

La AEPE garantiza el cumplimiento de la autoridad de la Secretaría del Interior, Secretaría de Comercio y en casos referentes a la importación o exportación de plantas, la Secretaría de Agricultura.

\section{¿Qué Prohibe la AEPE?}

La AEPE prohíbe la toma de cualquier especie amenazada. "Toma" bajo el Acta significa matar, trampear, cazar, colectar o dañar de cualquier manera a cualquier especie.

La definición de tomar ha sido extendida por cortes federales para incluir la destrucción de áreas designadas como "hábitats críticos", donde la destrucción puede ser razonablemente esperada y que resulte en una reducción en el número o distribución de una especie en peligro. Cualquier modificación adversa, así como la destrucción, de un hábitat critico es restringida bajo la AEPE.

\section{¿Qué es un Permiso?}

Las agencias que administran la AEPE están autorizadas para permitir excepciones, usualmente por medio de permisos limitados, a las prohibiciones contra las tomas. Los permisos pueden ser obtenidos para:

- Propósitos científicos.

- En casos donde el aplicante se hizo económicamente dependiente de la especie, antes que fuera declarada especie amenazada. Estos permisos son usualmente limitados para permitir "tomas" solamente por un año, en seguida que la especie fue designada como especie en peligro de extinción.

\section{¿Cuáles son los Castigos?}

Castigos civiles pueden ser aplicados por cualquiera de las agencias en cantidades de hasta $\$ 25,000$ por violación. Castigos penales por violaciones intencionadas pueden ser tan altos como $\$ 50,000$ por violación mas un año en prisión.

Las cortes están autorizadas para emitir avisos y demanda por daños, así como consignar búsquedas y capturas para hacer cumplir la AEPE. Además los ciudadanos privados pueden presentar juicios contra los violadores, incluyendo al gobierno, o contra las agencias para la aplicación de la AEPE. Las agencias pueden aun ir mas lejos, como hacer arrestos por violaciones del AEPE. También cualquier equipo o propiedad usado en la violación del AEPE puede ser declarado perdido y confiscado por las agencias.

\section{Fuente}

Código 16 de los Estados Unidos secciones 1531 a 1544. 